\title{
Postmenopausal hormone therapy and Alzheimer disease
}

\author{
A prospective cohort study \\ OPEN
}

Bushra Imtiaz, MD,

$\mathrm{MPH}$

Marjo Tuppurainen, MD, $\mathrm{PhD}$

Toni Rikkonen, $\mathrm{PhD}$

Miia Kivipelto, MD, PhD

Hilkka Soininen, MD,

$\mathrm{PhD}$

Heikki Kröger, MD, PhD

Anna-Maija Tolppanen, $\mathrm{PhD}$

Correspondence to

Dr. Imtiaz:

bushra.imtiaz@uef.fi

Supplemental data at Neurology.org

\section{ABSTRACT}

Objective: To explore the association between postmenopausal hormone therapy $(\mathrm{HT})$ and Alzheimer disease (AD).

Methods: Twenty-year follow-up data from the Kuopio Osteoporosis Risk Factor and Prevention study cohort were used. Self-administered questionnaires were sent to all women aged 47-56 years, residing in Kuopio Province starting in 1989 until 2009, every 5th year. Register-based information on HT prescriptions was available since 1995. Probable AD cases, based on DSM-IV and National Institute of Neurological and Communicative Disorders and Stroke-Alzheimer's Disease and Related Disorders Association criteria, were identified from the special reimbursement register (1999-2009). The study population included 8,195 women (227 cases of incident $A D$ ).

Results: Postmenopausal estrogen use was not associated with AD risk in register-based or selfreported data (hazard ratio/95\% confidence interval 0.92/0.68-1.2, 0.99/0.75-1.3, respectively). Long-term self-reported postmenopausal HT was associated with reduced AD risk (0.53/0.31-0.91). Similar results were obtained with any dementia diagnosis in the hospital discharge register as an outcome.

Conclusions: Our results do not provide strong evidence for a protective association between postmenopausal HT use and AD or dementia, although we observed a reduced AD risk among those with long-term self-reported HT use. Neurology ${ }^{\circledR}$ 2017;88:1062-1068

\section{GLOSSARY}

$\mathbf{A D}=$ Alzheimer disease; $\mathbf{B M I}=$ body mass index; $\mathbf{C E E}=$ conjugated equine estrogen; $\mathbf{D S M}-\mathbf{I V}=$ Diagnostic and Statistical Manual of Mental Disorders, 4th edition; HT = hormone therapy; ICD-10 = International Classification of Diseases-10; MPA = medroxyprogesterone acetate; SII = Social Insurance Institution; WHIMS = Women's Health Initiative Memory Study.

Alzheimer disease (AD), the most common form of dementia, accounts for $60 \%-80 \%$ of cases. ${ }^{1}$ Women have AD more often than men either due to their increased life expectancy ${ }^{2,3}$ or decline in sex steroid hormone levels around menopause, ${ }^{1,4}$ although some small studies have not detected this sex difference. ${ }^{5,6}$ Neuroprotective effects of estrogen have been observed in experimental animals, ${ }^{7-10}$ but clinical trials on postmenopausal hormone therapy (HT) use have not been successful, ${ }^{11-13}$ including the largest clinical trial to date, the Women's Health Initiative Memory Study (WHIMS). ${ }^{14}$ Observational studies support use of HT against AD if initiated around menopause in some ${ }^{15,16}$ but not all studies. ${ }^{17-20}$ Similarly, register-based studies have yielded conflicting results. ${ }^{18,20,21}$ Results from the Leisure World cohort revealed that the reduced risk of $\mathrm{AD}$ among $\mathrm{HT}$ users was a function of dose and duration. ${ }^{22,23}$

\footnotetext{
From the Institute of Clinical Medicine-Neurology (B.I., M.K., H.S.), Kuopio Musculoskeletal Research Unit, Clinical Research Center (M.T., T.R., H.K.), and Research Center for Comparative Effectiveness and Patient Safety (RECEPS) and School of Pharmacy (A.M.T.), University of Eastern Finland, Kuopio; Department of Obstetrics and Gynecology (M.T.), Neurocenter, Neurology (H.S.), and Department of Orthopedics and Traumatology (H.K.), Kuopio University Hospital, Finland; Department of Medicine (T.R.), University of Cambridge, UK; and Division of Clinical Geriatrics (M.K.), Center for Alzheimer Research, Karolinska Institutet and Karolinska University Hospital, Stockholm, Sweden.

The views expressed in this article are solely of the authors and not of any funding body. The funders had no role in data collection, management, analysis, interpretation, or review of the manuscript.

Go to Neurology.org for full disclosures. Funding information and disclosures deemed relevant by the authors, if any, are provided at the end of the article. The Article Processing Charge was paid by the authors.

This is an open access article distributed under the terms of the Creative Commons Attribution-NonCommercial-NoDerivatives License 4.0 (CC BY-NC-ND), which permits downloading and sharing the work provided it is properly cited. The work cannot be changed in any way or used commercially without permission from the journal.
} 
The aim of our study is to investigate the association of self-reported and registerrecorded postmenopausal $\mathrm{HT}$ use with $\mathrm{AD}$ in a longitudinal prospective cohort, while taking into account various socioeconomic and lifestyle-related $\mathrm{AD}$ risk factors.

METHODS Study population. The present study is based on the 20-year follow-up of the population of the Kuopio Osteoporosis Risk Factor and Prevention study cohort. A selfadministered baseline postal questionnaire was sent to all women aged 47-56 years who were residents of Kuopio Province, Eastern Finland $(\mathrm{n}=14,220)$, in February 1989. A total of $13,100(92.1 \%)$ women responded. The reasons for nonresponse were lack of address or residence not detected ( $\mathrm{n}=$ $119)$ and death $(\mathrm{n}=4)$. In addition, 947 women did not respond for other reasons and 50 returned a blank form. The 5 -year followup in 1994, 10-year follow-up in 1999, 15-year follow-up in 2004, and 20-year follow-up in 2009 was mailed to the 13,100 , $12,562,12,075$, and 11,420 women, respectively. A total of 11,954 (91.2\%), 11,538 (91.8\%), 10,926 (90.4\%), and 8,195 (71.8\%) women responded to the 5-, 10-, 15-, and 20-year followups, respectively. The questionnaires were sent to women who had responded to the baseline inquiry, were alive, and had a valid postal address at that time.

The baseline questionnaire covered demographics, lifestyle, medical issues, and other characteristics such as age, height, weight, smoking, alcohol consumption, health disorders diagnosed by a physician, reproductive history, type and duration of HT use, operations, occupation, and physical activity. These questionnaires were repeated in the follow-up inquiries.

The present study included those 8,195 women who had complete data on confounders and self-reported exposure. Outcome data and register-based exposure data were available for all participants.

Outcomes. The main outcome of our study was clinically verified AD diagnosis. These diagnoses from 1999-2009 were identified from the Finnish special reimbursement register maintained by the Social Insurance Institution (SII). The register contains information on the reimbursed drugs used for chronic illnesses such as $\mathrm{AD}$. The Finnish special reimbursement register possesses high validity and positive predictive value for $\mathrm{AD}$ diagnosis. ${ }^{24} \mathrm{The}$ Finnish Current Care Guideline recommends that all persons with $\mathrm{AD}$ are treated with antidementia drugs unless there is a specific contraindication (such as gastric ulcer/intestinal tract operation $<6$ months ago or severe asthma or chronic obstructive pulmonary disease for acetylcholinesterase inhibitors). ${ }^{25}$ In Finland, the diagnosis of probable AD is based on DSM-IV criteria for $\mathrm{AD}$ and National Institute of Neurologic and Communicative Disorders and Stroke-Alzheimer Disease and Related Disorders Association. ${ }^{26,27}$ The main diagnostic criteria were progressive decline in memory and cognition and exclusion of other reasons. Diagnosis of AD was supported by abnormal MRI or CSF biomarker findings typical for AD.

To be eligible for reimbursed $\mathrm{AD}$ medication (acetylcholinesterase inhibitors or memantine), a medical statement of a clinically verified AD diagnosis needs to be submitted to SII. Thus, case identification is carried out in clinics but is reconfirmed by SII. Summary of anamnestic information from the patients and family, as well as findings, e.g., MRI/CT, laboratory tests, and Consortium to Establish a Registry for Alzheimer's Disease, are submitted to the SII, where a geriatrician/neurologist systematically evaluates the diagnostic evidence for each $\mathrm{AD}$ case and confirms whether the prespecified criteria are met excluding possible alternative diagnoses for memory impairment such as severe depression, metabolic disturbances, and other forms of dementia such as vascular dementia without $\mathrm{AD}$-like symptoms.

We also performed sensitivity analyses with dementia as an outcome. These data were extracted from the National Hospital Discharge register using the following ICD-10 codes: F00-F03 (F00, dementia in Alzheimer disease; F01, vascular dementia; F02, dementia in other diseases classified elsewhere; F03, unspecified dementia) and G30 (Alzheimer disease, early/late onset). This register includes all inpatient admissions. Diagnosis codes for each admission are recorded by attending physician. All Finnish citizens/long-term residents are covered by tax-supported public health service.

Use of HT. Self-reported HT use was recorded as lifetime use in years (and indication of use) at the baseline inquiry in 1989. In all follow-up questionnaires, numbers of months per year of estrogen use were reported and the duration of self-reported estrogen use was calculated on basis of these questionnaires. Current medication prescribed by a physician, duration and purpose of use, and name of tablets used were asked in all inquiries. To exclude the possibility of recall bias in the self-reported questionnaires, we accessed the prescription register data to ascertain HT use. Vaginal products were excluded. HT was defined from the registry as those preparations having systemic estrogenic properties belonging to the following codes of ATC classification: G03C (estrogens), G03F (estrogen and progesterone) excluding oral contraceptives. Self-reported use of estrogen was categorized into postmenopausal HT based on use after the onset of menopause.

Covariates. Baseline menopause status was categorized to 5 categories: (1) menstruating, no HT; (2) true menopause; (3) menstruating, HT 1-30 years; (4) hysterectomy and HT, no oophorectomy; (5) unclear (hysterectomy, no data on oophorectomy or HT use). When categorizing the self-reported HT to postmenopausal use, a woman was considered postmenopausal if $\geq 12$ months had passed since her natural menstrual cycle, if she had undergone surgical menopause through bilateral oophorectomy with or without hysterectomy, or if the time since menopause and the history of HT use could be clarified from the follow-up questionnaire. For the present study, we used data on natural menopause (i.e., date of last menstruation, collected through self-reports at baseline and 5-year follow-up assessments). Over $90 \%$ of women were postmenopausal at the second follow-up. Missing information was collected from participants by telephone. Body mass index (BMI) was calculated as the ratio of weight in kilograms to height in meters squared and was based on self-reporting.

Physical activity was inquired through self-reported data in 3 ways at baseline and in all follow-up surveys as follows: leisure time physical activity as well as asking about how physically demanding work was in the last year; ambulatory status as capability and extent of movement, need of aids in movement, and history of joint degeneration; and amount of physical activity, including winter and summer activities, amount of current regular physical activity, and its duration (hours per week). Of these 3 categories, the amount of physical activity was the most predictive of $\mathrm{AD}$ and thus was included in the analyses.

Data on education were obtained in self-reported data only from a subcohort undergoing bone marrow density measurement. Education was categorized into 4 groups: compulsory schooling, compulsory schooling + maximum 2 years of 
supplementary school or occupational training, high school + minimum 2 years of supplementary school or professional training, and university degree. To assess whether the adjustment for education affected the results, we conducted a separate sensitivity analyses in the subcohort for whom we had education data $(\mathrm{n}=2,383)$. History of ever/never smoking was asked in all selfreported questionnaires along with regularity of smoking, number of years of smoking, and number of cigarettes smoked per day.

Data on self-reported occupation were gathered under 9 different categories (managers; professionals; technicians and associate professionals; clerical support workers; service and sales workers; skilled agricultural, fish, and forestry; crafts and related trades workers; plant and machine operators; other occupation; and housewife/pensioner/caregiver/no occupation) but converted into a dichotomous variable (employed and unemployed) for the analyses. Alcohol consumption was inquired in questionnaires as the amount of alcohol beverages consumed during a 1-month period and converted into grams of alcohol intake per month.

At baseline, women were asked in questionnaire about the age at menarche, age at menopause, number of pregnancies, number of live births, and abortions. Abortion was inquired in questionnaire as "Number of times interrupting pregnancies due to abortion/miscarriage." A history of any gynecologic operations (caesarian sections and sterilizations) was also obtained, as well as what, if anything, was removed in these operations (uterus, ovary, part of both, cervix, or other parts of genitals).

Standard protocol approvals, registrations, and patient consents. The study design was approved by the Ethics Committee of Kuopio University Hospital and written informed consent was obtained from all participants.

Statistical analysis. Statistical analysis was carried out with Stata 12.0 (Stata Corp LP, College Station, TX). The characteristics of women with respect to $\mathrm{AD}$ incidence were compared using $\chi^{2}$ test for categorical variables and $t$ test for continuous variables. Correlation between confounders and exposure were investigated with the Spearman correlation coefficient. As expected, hysterectomy and oophorectomy were strongly correlated $(r=$ 0.561 ) and were thus combined into one variable (surgery). There were no other indications of collinearity $(r<0.4)$.

Cox proportional hazard models were used to evaluate the association between HT use and AD incidence. Separate analyses were carried out for different durations of use and different types of HT. Hazard ratios and $95 \%$ confidence intervals were estimated with age-adjusted model and model adjusted for age, BMI, alcohol, smoking, physical activity, occupation status, number of births, menopause status, any cancer, and surgery. Since the education data were available for only a subset of participants, sensitivity analyses were conducted in this group separately. Association between HT and dementia was studied similarly.

We studied whether the association between $\mathrm{HT}$ and $\mathrm{AD}$ was different among women who had undergone oophorectomy or hysterectomy by assessing the interaction of hysterectomy or oophorectomy and self-reported and register-recorded HT use. There was no evidence for effect modification by these surgeries (All $p$ values for interaction were $>0.6$ ) and thus stratified analyses were not performed.

RESULTS Average age at AD diagnosis was 72.3 years (range 59.2-78.6 years). Women who later developed $\mathrm{AD}$ were significantly older than women without $\mathrm{AD}$. They also reported less physical activity and were more likely to be unemployed than women who were not diagnosed with $\mathrm{AD}$ during the follow-up. Number of childbirths, abortions, and pregnancies was similar between groups, but women who developed $\mathrm{AD}$ were more likely to be menopausal at baseline than those who were not diagnosed with AD. Register-reported HT or oophorectomy/hysterectomy was not associated with $\mathrm{AD}$ in these univariable analyses (table e-1 at Neurology.org).

Table 1 Risk of developing Alzheimer disease (AD) among hormone therapy (HT) users (according to type of therapy used) in the whole cohort $(n=8,195)$

\begin{tabular}{|c|c|c|c|c|c|}
\hline HT & $\begin{array}{l}\text { Incidence } \\
\text { of } A D / 1,000 \\
\text { person-years }\end{array}$ & Model 1 AD & & \multicolumn{2}{|l|}{ Model 2 AD } \\
\hline \multicolumn{6}{|c|}{ Any HT use (register-based, since 1995) } \\
\hline No & 1.7 & 1.00 (reference) & & 1.00 (reference) & \\
\hline Yes & 1.4 & $1.10(0.85-1.40)$ & 0.488 & $1.10(0.83-1.40)$ & 0.588 \\
\hline \multicolumn{6}{|c|}{ Estrogen use (register-based, since 1995) } \\
\hline No & 1.7 & 1.00 (reference) & & 1.00 (reference) & \\
\hline Yes & 1.4 & $0.98(0.74-1.30)$ & 0.903 & $0.92(0.68-1.20)$ & 0.611 \\
\hline \multicolumn{6}{|c|}{ Combination therapy (register-based, since 1995) } \\
\hline No & 1.6 & 1.00 (reference) & & 1.00 (reference) & \\
\hline Yes & 1.4 & $1.10(0.85-1.50)$ & 0.406 & $1.10(0.87-1.50)$ & 0.325 \\
\hline \multicolumn{6}{|c|}{ Self-reported estrogen use } \\
\hline No & 1.7 & 1.00 (reference) & & 1.00 (reference) & \\
\hline Yes & 1.5 & $1.00(0.82-1.30)$ & 0.750 & $0.99(0.75-1.30)$ & 0.928 \\
\hline
\end{tabular}

Model 1: adjusted for age. Model 2: adjusted for age, body mass index, alcohol, smoking, physical activity, occupation status, number of births, menopause status, any cancer, and oophorectomy and hysterectomy. 


\begin{tabular}{|c|c|c|c|c|c|}
\hline \multirow[t]{3}{*}{ Table 2} & \multicolumn{5}{|c|}{$\begin{array}{l}\text { Risk of developing Alzheimer disease (AD) among hormone therapy (HT) users (register-based) with } \\
\text { different durations of HT use in the whole cohort }(n=8,195)\end{array}$} \\
\hline & & \multicolumn{2}{|l|}{ Model 1} & \multicolumn{2}{|l|}{ Model 2} \\
\hline & $\begin{array}{l}\text { Incidence of AD/1,000 } \\
\text { person-years }\end{array}$ & HR (95\% Cl) & $p$ Value & HR (95\% Cl) & p Value \\
\hline \multicolumn{6}{|c|}{ Duration of estrogen use, $y$} \\
\hline None & 1.6 & 1.00 (reference) & & 1.00 (reference) & \\
\hline$<1$ & 1.3 & $0.89(0.52-1.50)$ & 0.670 & $0.85(0.49-1.50)$ & 0.572 \\
\hline $1-3$ & 1.6 & $1.20(0.71-1.90)$ & 0.539 & $1.10(0.66-1.80)$ & 0.728 \\
\hline $3-5$ & 1.6 & $1.20(0.65-2.10)$ & 0.583 & $1.10(0.59-1.90)$ & 0.797 \\
\hline $5-10$ & 1.3 & $0.88(0.49-1.60)$ & 0.675 & $0.78(0.42-1.40)$ & 0.425 \\
\hline$>10$ & 0.39 & $0.29(0.04-2.10)$ & 0.221 & $0.26(0.03-1.80)$ & 0.184 \\
\hline \multicolumn{6}{|c|}{ Duration of combination therapy use, $y$} \\
\hline None & 1.6 & 1.00 (reference) & & 1.00 (reference) & \\
\hline$<1$ & 2.2 & $1.60(1.10-2.40)$ & 0.018 & $1.70(1.10-2.60)$ & 0.011 \\
\hline $1-3$ & 1.3 & $1.00(0.60-1.80)$ & 0.889 & $1.10(0.62-1.90)$ & 0.786 \\
\hline $3-5$ & 0.45 & $0.35(0.11-1.10)$ & 0.072 & $0.36(0.11-1.10)$ & 0.080 \\
\hline $5-10$ & 1.6 & $1.40(0.86-2.20)$ & 0.172 & $1.40(0.88-2.30)$ & 0.148 \\
\hline$>10$ & 1.7 & $1.50(0.65-3.30)$ & 0.349 & $1.40(0.64-3.30)$ & 0.372 \\
\hline
\end{tabular}

Abbreviations: $\mathrm{Cl}=$ confidence interval; $\mathrm{HR}=$ hazard ratio.

Model 1: adjusted for age. Model 2: adjusted for age, body mass index, alcohol, smoking, physical activity, occupation status, number of births, menopause status, any cancer, and surgery.

Table 1 shows the relative risk of $\mathrm{AD}$ according to both register-based and self-reported HT use (yes/ no). Neither register-based nor self-reported HT use was associated with $\mathrm{AD}$ risk. The results were similar in the sensitivity analyses conducted among those with data on education $(n=2,383$; tables e- 2 and e-3), i.e., no association was detected between HT use (any HT, estrogen, or combination therapy; either register-based or self-reported) and $\mathrm{AD}$.

HT use when categorized according to duration register-based $\mathrm{HT}$ use was not associated with $\mathrm{AD}$ (table 2). However, when self-reported data were used, those with longest self-reported HT use $>10$ years had lower risk of $\mathrm{AD}$ in comparison to nonusers (table 3) also after adjusting for lifestyle and socioeconomic confounders and variables related to estrogen status. Sensitivity analyses with any dementia as an outcome produced similar results to those shown in tables 1-3, although the association between $>10$ years $\mathrm{HT}$ use and $\mathrm{AD}$ was attenuated and its confidence also included 1 in the sensitivity analyses (tables e-4 to e-6).

DISCUSSION The findings from our large prospective cohort study do not provide strong evidence for an association between postmenopausal HT use and

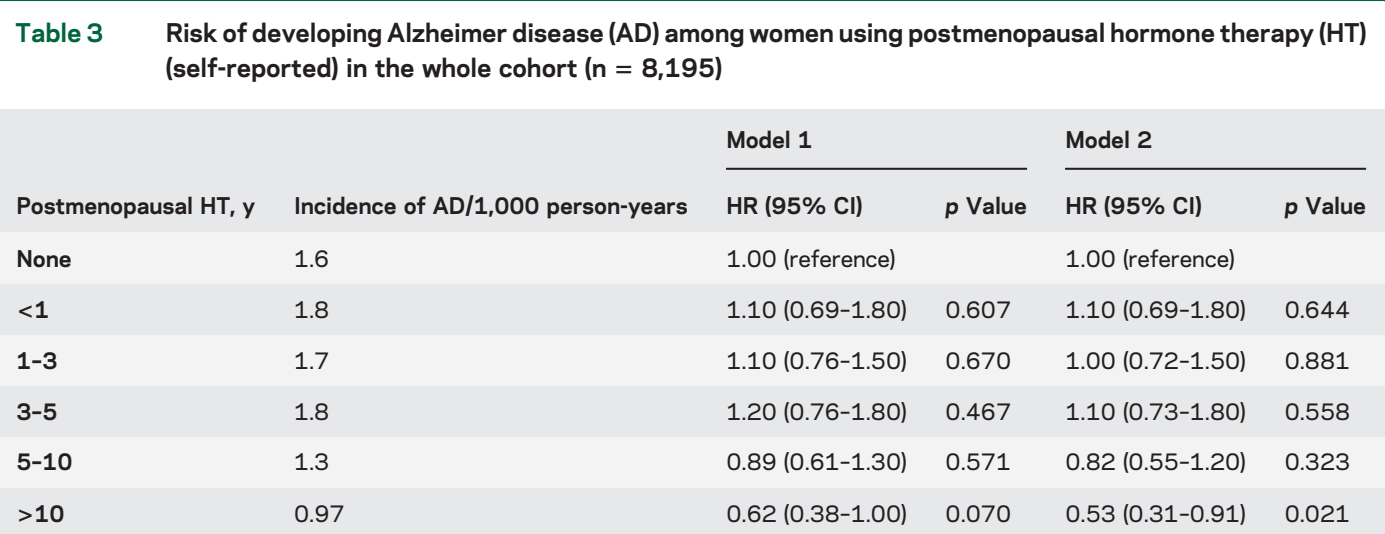

Abbreviations: $\mathrm{Cl}=$ confidence interval; $\mathrm{HR}=$ hazard ratio.

Model 1: adjusted for age. Model 2: adjusted for age, body mass index, alcohol, smoking, physical activity, occupation status, number of births, menopause status, any cancer, and surgery. 
$\mathrm{AD}$ or dementia, although a protective association between long-term ( $>10$ years) self-reported use of $\mathrm{HT}$ and $\mathrm{AD}$ was observed. This finding indirectly favors the effectiveness of HT if started in the early postmenopausal period (critical window theory). Another explanation for this association can be reverse causation, i.e., $\mathrm{AD}$ (or more precisely, its preclinical symptoms) affecting the exposure to HT (or reporting of HT duration in the self-reported data), or a chance finding. The association with longer duration of HT use was only found in selfreported postmenopausal estrogen use, not for register-based HT use after 1995, and the association was less evident when all dementia diagnoses instead of clinically verified $\mathrm{AD}$ diagnosis were used as an outcome. One explanation for the different results with self-reported and register-based exposure could be different time period as register data were not available before 1995, which is 7 years after the baseline inquiry. Thus, the registerbased data after 1995 would misclassify those who discontinued HT use before 1995 as nonusers. It is unlikely that this misclassification was differential in those who later developed $\mathrm{AD}$ and those who did not. Therefore it would lead to an underestimation of the association between $\mathrm{HT}$ use and $\mathrm{AD}$ with the register-based data after 1995. An alternative explanation is recall bias, but this is unlikely as previous validation study from the same cohort showed that a postal inquiry is a reliable method of recording long-term HT use in Finnish postmenopausal women. ${ }^{28}$

Our result is in line with the extended follow-up of the Cache County Study, which detected a reduced $\mathrm{AD}$ risk if $\mathrm{HT}$ was started within 5 years of menopause and continued for more than 10 years. ${ }^{15}$ The largest clinical trial on HT-all cause dementia association, i.e., WHIMS, assessed cognitive performance of women $>65$ years old, assigned to conjugated equine estrogen (CEE; unopposed therapy) vs placebo or continuous CEE + medroxyprogesterone acetate (CEE + MPA; opposed therapy) vs placebo. The use of opposed HT increased the dementia risk, but this did not occur with unopposed HT. ${ }^{14,29}$ In the WHIMS trial, women were randomized to receive opposed therapy as CEE combined with MPA. In Finland, estradiol in combination with norethisterone or levonorgestrel (not MPA) is used among women with intact uterus ${ }^{30}$ and only estradiol is used mainly among women undergoing hysterectomy. ${ }^{31}$ The difference between these 2 studies may be attributable to the differences in the effects exerted by the different estrogen preparations. In addition, the women in our cohort were around 10 years younger than women in the WHI trial, and the main outcome in our study was $\mathrm{AD}$, while it was all-cause dementia in WHIMS.
One cohort study reported that an early initiation of HT around menopause was protective against AD. ${ }^{32}$ Similar findings were reported from the Multi-Institutional Research in Alzheimer Genetic Epidemiology study, where HT use in the youngest age tertiles (50-63 years) protected against $\mathrm{AD}$ in comparison to those in the older age tertiles. ${ }^{33}$

The lack of association in our cohort between any HT use (all users of HT, not taking into account either the time of initiation or the duration of therapy) and $\mathrm{AD} /$ dementia is consistent with previous observational studies where HT was categorized as former or current use and lifetime estrogen exposure was taken into account. ${ }^{34,35}$ Postmenopausal estrogen therapy was not protective against $\mathrm{AD}$ in 2 of the case-control studies. ${ }^{18,20}$ This discrepancy in observational studies is explained by differences in outcome measurement, number of observations, duration, type, and the time of initiation of HT use.

The strengths of our study include its large sample size, long follow-up time, relatively homogenous population, clinically verified $\mathrm{AD}$ cases, prescriptionbased validation of HT use, and control for various important comorbidities. Confounders and exposures were measured with the same questions during the follow-up. In addition, the positive predictive value of AD diagnosis in the Special Reimbursement Register is high. ${ }^{24}$ However, it is likely that this register does not capture all $\mathrm{AD}$ cases, or persons with other forms of dementia. Therefore we conducted sensitivity analysis with any dementia as an outcome. Despite these strengths, our study has some limitations: first, information was collected by self-reported postal inquiries, which may be subject to recall bias; second, the effect of healthy user bias among the long-term users cannot be overlooked; third, register data on HT use and AD diagnosis were available from 1995 to 1999 onwards, respectively; fourth, we cannot eliminate the chance of a survival bias contributing to the protective association observed among the longest HT users; fifth, we were not able to control the results for genetic predisposition to $\mathrm{AD}$ (APOE status and familial $\mathrm{AD}$ ). However, it is unlikely that these genetic factors would influence start of HT use and thus it is unlikely that the results are confounded by genetic background.

Misclassification of outcome (i.e., undiagnosed $\mathrm{AD}$ or dementia cases) is possible and this would dilute our estimates towards the null. However, the proportion of misclassified persons is likely to be small. Due to our outcome data source in sensitivity analyses for dementia, we captured only those persons with dementia who required inpatient admission (due to dementia or other disease/accident). The diagnostic process for dementia often begins in an outpatient setting, but these settings were not included in the 
hospital discharge register. Therefore, those persons with dementia who did not have any hospital admissions or antidementia medications were misclassified.

Our study examined a homogenous population (residents of Kuopio Province, all accessed via the national social security system), thus decreasing the chances of selection bias or confounding by socioeconomic-related factors. Some previous observational studies carried out in sociodemographic homogenous populations have observed decreased risk of $\mathrm{AD}$ among HT users. ${ }^{23,36,37}$ Estrogen replacement therapy was protective against $\mathrm{AD}$ in these studies $^{23,37}$ and sociodemographic heterogeneity may account for the contrasting results obtained in the 2 observational studies. ${ }^{18,20}$

Our results based on 2 decades of follow-up of a large homogenous population did not provide strong evidence for a protective association between postmenopausal $\mathrm{HT}$ use and $\mathrm{AD}$ or dementia.

\section{AUTHOR CONTRIBUTIONS}

Dr. Imtiaz: planned the research project, drafted the first version of the manuscript, performed statistical analyses, acts as guarantor, accepted the submitted version of the manuscript, and made important intellectual contribution to draft versions. Dr. Tuppurainen: planned the research project, participated in data collection, accepted the submitted version of the manuscript, and made important intellectual contribution to draft versions. Dr. Rikkonen: participated in data analysis, accepted the submitted version of the manuscript, and made important intellectual contribution to draft versions. Prof. Kivipelto: accepted the submitted version of the manuscript and made important intellectual contribution to draft versions. Prof. Soininen: planned the research project, accepted the submitted version of the manuscript, and made important intellectual contribution to draft versions. Prof. Kröger: planned the research project, participated in data collection, accepted the submitted version of the manuscript, and made important intellectual contribution to draft versions. Dr. Tolppanen: planned the research project, supervised data analyses and the research project, accepted the submitted version of the manuscript, and made important intellectual contribution to draft versions.

\section{ACKNOWLEDGMENT}

The authors thank Seija Oinonen for technical help regarding data extraction.

\section{STUDY FUNDING}

Supported by Kuopio Osteoporosis Risk Factor and Prevention (OSTPRE) grant 250707. A.M.T. acknowledges funding from European Regional Development Fund (regional council of Pohjois Savo), M.K. is a recipient of Academy of Finland and Center for Innovative Medicine (CIMED), and H.S. received funding from the University of Eastern Finland for UEF Brain. B.I. acknowledges The Finnish Cultural Foundation (central fund) and funding by Doctoral Program of Molecular Medicine, University of Eastern Finland.

\section{DISCLOSURE}

The authors report no disclosures relevant to the manuscript. Go to Neurology.org for full disclosures.

Received May 6, 2016. Accepted in final form December 21, 2016.

\section{REFERENCES}

1. Alzheimer's Association. 2016 Alzheimer's disease facts and figures. Alzheimers Dement 2016;12.
2. Hebert LE, Scherr PA, McCann JJ, Beckett LA, Evans DA. Is the risk of developing Alzheimer's disease greater for women than for men? Am J Epidemiol 2001;153:132-136.

3. Seshadri S, Wolf PA, Beiser A, et al. Lifetime risk of dementia and Alzheimer's disease: the impact of mortality on risk estimates in the Framingham Study. Neurology 1997;49:1498-1504.

4. Vest RS, Pike CJ. Gender, sex steroid hormones, and Alzheimer's disease. Horm Behav 2013;63:301-307.

5. Yoshitake T, Kiyohara Y, Kato I, et al. Incidence and risk factors of vascular dementia and Alzheimer's disease in a defined elderly Japanese population: the Hisayama Study. Neurology 1995;45:1161-1168.

6. Nilsson LV. Incidence of severe dementia in an urban sample followed from 70 to 79 years of age. Acta Psychiatr Scand 1984;70:478-486.

7. Brinton RD, Chen S, Montoya M, Hsieh D, Minaya J. The estrogen replacement therapy of the Women's Health Initiative promotes the cellular mechanisms of memory and neuronal survival in neurons vulnerable to Alzheimer's disease. Maturitas 2000;34(suppl 2):S35-S52.

8. Gibbs RB. Estrogen therapy and cognition: a review of the cholinergic hypothesis. Endocr Rev 2010;31:224-253.

9. Tanapat P, Hastings NB, Reeves AJ, Gould E. Estrogen stimulates a transient increase in the number of new neurons in the dentate gyrus of the adult female rat. J Neurosci 1999;19:5792-5801.

10. Behl C. Oestrogen as a neuroprotective hormone. Nat Rev Neurosci 2002;3:433-442.

11. Henderson VW, Paganini-Hill A, Miller BL, et al. Estrogen for Alzheimer's disease in women: randomized, double-blind, placebo-controlled trial. Neurology 2000;54:295-301.

12. Mulnard RA, Cotman CW, Kawas C, et al. Estrogen replacement therapy for treatment of mild to moderate Alzheimer disease: a randomized controlled trial: Alzheimer's Disease Cooperative Study. JAMA 2000;283: 1007-1015.

13. Wang PN, Liao SQ, Liu RS, et al. Effects of estrogen on cognition, mood, and cerebral blood flow in AD: a controlled study. Neurology 2000;54:2061-2066.

14. Shumaker SA, Legault C, Rapp SR, et al; WHIMS Investigators. Estrogen plus progestin and the incidence of dementia and mild cognitive impairment in postmenopausal women: the Women's Health Initiative Memory Study: a randomized controlled trial. JAMA 2003;289: 2651-2662.

15. Shao H, Breitner JC, Whitmer RA, et al; Cache County Investigators. Hormone therapy and Alzheimer disease dementia: new findings from the Cache County Study. Neurology 2012;79:1846-1852.

16. Whitmer RA, Quesenberry CP, Zhou J, Yaffe K. Timing of hormone therapy and dementia: the critical window theory revisited. Ann Neurol 2011;69:163-169.

17. Barnes LL, Wilson RS, Schneider JA, Bienias JL, Evans DA, Bennett DA. Gender, cognitive decline, and risk of AD in older persons. Neurology 2003;60:1777-1781.

18. Brenner DE, Kukull WA, Stergachis A, et al. Postmenopausal estrogen replacement therapy and the risk of Alzheimer's disease: a population-based case-control study. Am J Epidemiol 1994;140:262-267.

19. Roberts RO, Cha RH, Knopman DS, Petersen RC, Rocca WA. Postmenopausal estrogen therapy and Alzheimer disease: overall negative findings. Alzheimer Dis Assoc Disord 2006;20:141-146. 
20. Seshadri S, Zornberg GL, Derby LE, Myers MW, Jick H, Drachman DA. Postmenopausal estrogen replacement therapy and the risk of Alzheimer disease. Arch Neurol 2001;58:435-440.

21. Waring SC, Rocca WA, Petersen RC, O'Brien PC, Tangalos EG, Kokmen E. Postmenopausal estrogen replacement therapy and risk of $\mathrm{AD}$ : a population-based study. Neurology 1999;52:965-970.

22. Paganini-Hill A, Henderson VW. Estrogen deficiency and risk of Alzheimer's disease in women. Am J Epidemiol 1994;140:256-261.

23. Paganini-Hill A, Henderson VW. Estrogen replacement therapy and risk of Alzheimer disease. Arch Intern Med 1996;156:2213-2217.

24. Solomon A, Ngandu T, Soininen H, Hallikainen MM, Kivipelto M, Laatikainen T. Validity of dementia and Alzheimer's disease diagnoses in Finnish national registers. Alzheimers Dement 2014;10:303-309.

25. Suhonen J, Pirttila T, Erkinjuntti T, et al. Suomalaisen laakariseuran duodecimin, societas gerontologica Fennican, suomen neurologisen yhdistyksen, suomen psykogeriatrisen yhdistyksen, suomen yleislaaketieteen yhdistyksen asettama tyoryhma, update on current care guidelines: the diagnosis and medical treatment of memory disorders. Duodecim 2010;126:2167-2168.

26. Quick Reference to the Diagnostic Criteria From DSM-IVTR. Washington, DC:American Psychiatric Association; 2000.

27. McKhann G, Drachman D, Folstein M, Katzman R, Price D, Stadlan EM. Clinical diagnosis of Alzheimer's disease: report of the NINCDS-ADRDA Work Group under the auspices of Department of Health and Human Services Task Force on Alzheimer's Disease. Neurology 1984;34:939-944.

28. Sandini L, Pentti K, Tuppurainen M, Kroger H, Honkanen R. Agreement of self-reported estrogen use with prescription data: an analysis of women from the Kuopio Osteoporosis Risk Factor and Prevention Study. Menopause 2008;15: 282-289.
29. Shumaker SA, Legault C, Kuller L, et al; Women's Health Initiative Memory Study. Conjugated equine estrogens and incidence of probable dementia and mild cognitive impairment in postmenopausal women: Women's Health Initiative Memory Study. JAMA 2004;291:2947-2958.

30. Pentti K, Tuppurainen MT, Honkanen R, et al. Hormone therapy protects from diabetes: the Kuopio osteoporosis risk factor and prevention study. Eur J Endocrinol 2009; 160:979-983.

31. Pentti K, Honkanen R, Tuppurainen MT, Sandini L, Kroger H, Saarikoski S. Hormone replacement therapy and mortality in 52- to 70-year-old women: the Kuopio osteoporosis risk factor and prevention study. Eur J Endocrinol 2006;154:101-107.

32. Bagger YZ, Tanko LB, Alexandersen P, Qin G, Christiansen C; PERF Study Group. Early postmenopausal hormone therapy may prevent cognitive impairment later in life. Menopause 2005;12:12-17.

33. Henderson VW, Benke KS, Green RC, Cupples LA, Farrer LA; MIRAGE Study Group. Postmenopausal hormone therapy and Alzheimer's disease risk: interaction with age. J Neurol Neurosurg Psychiatry 2005;76: 103-105.

34. Ryan J, Carriere I, Scali J, et al. Characteristics of hormone therapy, cognitive function, and dementia: the prospective 3C Study. Neurology 2009;73:1729-1737.

35. Ryan J, Carriere I, Scali J, Ritchie K, Ancelin ML. Lifetime estrogen exposure and cognitive functioning in later life. Psychoneuroendocrinology 2009;34:287-298.

36. Zandi PP, Carlson MC, Plassman BL, et al; Cache County Memory Study Investigators. Hormone replacement therapy and incidence of Alzheimer disease in older women: the Cache County Study. JAMA 2002;288:2123-2129.

37. Kawas C, Resnick S, Morrison A, et al. A prospective study of estrogen replacement therapy and the risk of developing Alzheimer's disease: the Baltimore Longitudinal Study of Aging. Neurology 1997;48:1517-1521.

\section{Minutes Pack a Punch}

\section{Neurology ${ }^{\circledR}$ Podcasts}

- Interviews with top experts on new clinical research in neurology

- Editorial comments on selected articles

- Convenient-listen during your commute, at your desk, or even at the gym

- On demand-it's there when you want it

- Fun and engaging

- New topic each week

- FREE

Listen now at www.aan.com/podcast 


\section{Neurology}

Postmenopausal hormone therapy and Alzheimer disease: A prospective cohort study Bushra Imtiaz, Marjo Tuppurainen, Toni Rikkonen, et al.

Neurology 2017;88;1062-1068 Published Online before print February 15, 2017

DOI 10.1212/WNL.0000000000003696

This information is current as of February 15, 2017

\section{Updated Information \& Services \\ Supplementary Material}

\section{References}

Citations

Subspecialty Collections

Permissions \& Licensing

Reprints including high resolution figures, can be found at: http://n.neurology.org/content/88/11/1062.full

Supplementary material can be found at: http://n.neurology.org/content/suppl/2017/02/15/WNL.0000000000003 696.DC1

http://n.neurology.org/content/suppl/2017/05/01/WNL.0000000000003 696.DC2

http://n.neurology.org/content/suppl/2018/03/27/WNL.0000000000003 696.DC3

This article cites 35 articles, 14 of which you can access for free at: http://n.neurology.org/content/88/11/1062.full\#ref-list-1

This article has been cited by 2 HighWire-hosted articles: http://n.neurology.org/content/88/11/1062.full\#\#otherarticles

This article, along with others on similar topics, appears in the following collection(s):

Alzheimer's disease

http://n.neurology.org/cgi/collection/alzheimers_disease

Cohort studies

http://n.neurology.org/cgi/collection/cohort_studies

Information about reproducing this article in parts (figures,tables) or in its entirety can be found online at:

http://www.neurology.org/about/about_the_journal\#permissions

Information about ordering reprints can be found online:

http://n.neurology.org/subscribers/advertise

Neurology ${ }^{\circledR}$ is the official journal of the American Academy of Neurology. Published continuously since 1951, it is now a weekly with 48 issues per year. Copyright Copyright ( 2017 The Author(s). Published by Wolters Kluwer Health, Inc. on behalf of the American Academy of Neurology. All rights reserved. Print ISSN: 0028-3878. Online ISSN: 1526-632X.

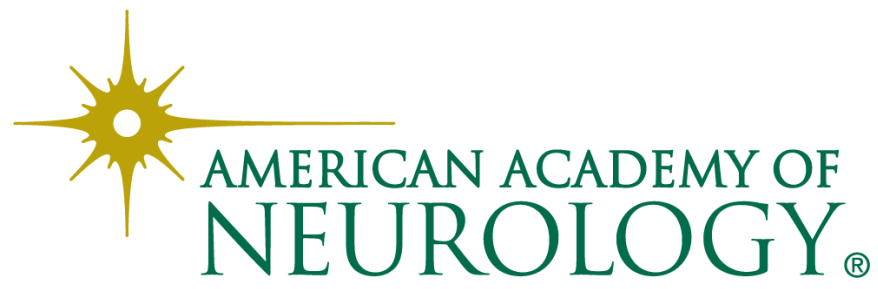

